Review

\title{
Role of certain nutritional supplements and biological regulators in the epilepsy
}

\author{
Mohammad Asif \\ Department of pharmacy, GRD(PG)IMT, Dehradun, (Uttarakhand), 248009, India
}

\begin{abstract}
Certain dietary contents, biological supplements might influence the occurrence or treatment of epilepsy. Some studies have found that the supplementation with individual nutrients reduced seizure frequency or improved other aspects of health in patients with epilepsy. Potentially beneficial dietary interventions include treating blood glucose dysregulations. Identifying and avoiding allergenic foods, and avoiding suspected triggering agents such as alcohol, aspartame, and monosodium glutamate. The Atkins diet (very low in carbohydrates) is a less restrictive type diet that may be effective in some cases. Nutrients that may reduce seizure frequency include vitamin B6, magnesium, vitamin E, manganese, taurine, dimethylglycine, and omega-3 fatty acids. Administration of thiamine may improve cognitive function in patients with epilepsy. Supplementation with folic acid, vitamin B6, biotin, vitamin D, and L-carnitine may be needed to prevent or treat deficiencies resulting from the use of anticonvulsant drugs. Vitamin K1 has been recommended near the end of pregnancy for women taking anticonvulsants. Melatonin may reduce seizure frequency in some cases, and progesterone may be useful for women with cyclic exacerbations of seizures. In most cases, nutritional therapy is not a substitute for anticonvulsant medications. However, in selected cases, depending on the effectiveness of the interventions, dosage reductions or discontinuation of medications may be possible. However, nutrient supplementation may be necessary to prevent or reverse the effects of certain deficiencies that frequently result from the use of antiepileptic drugs.
\end{abstract}

Keywords seizure, epilepsy, food, nutrient, vitamins, hormones

\section{INTRODUCTION}

Epilepsy can develop in any person at any age. Almost $1 \%$ of people will develop epilepsy during their lifetime. New cases of epilepsy are most common among children, especially during the first year. The rate of new cases gradually declines until about age 10 and then become stable. After age 60, the rate starts to increase again. The causes of epilepsy can be divided into two groups: brain injuries and chemical imbalances in the brain. Anything that injures the brain can lead to seizures. But in over half the cases no cause can be identified. The type of injury that can lead to a seizure is age-dependent. Seizures in children often are caused by birth traumas, infections, such as meningitis, congenital abnormalities or high fevers. Seizures in the middle years commonly are caused by head injuries, infections, alcohol, stimulant drugs or medication side effects. In the elderly, brain tumors and strokes cause a higher proportion of seizures. Not all seizures result from a structural problem in the brain. Chemical imbalances also can cause seizures. Common chemical imbalances that can produce seizures include drugs like alcohol, cocaine and others, low blood sugar, low oxygen, low blood sodium or low blood calcium (Goutieres and Aicardi, 1985; Grant, 2004; Grant and Stores, 1970; Guidolin et al., 1998; Hansson et al., 1976; Higashi et al., 1980; Hiilesmaa et al., 1983; Hom et al., 1991; Johnson, 1982). Kidney failure or liver failure can also produce

*Correspondence: Mohammad Asif

E-mail: aasif321@gmail.com

Received July 21, 2013; Accepted October 28, 2013; Published November 30, 2013

doi: http://dx.doi.org/10.5667/tang.2013.0020

C2013 by Association of Humanitas Medicine seizures. Although these disorders and injuries can explain many cases of epilepsy, often the cause of epilepsy remains idiopathic. About half the time no cause for seizure can be identified. Fortunately, we do not need to know the cause to treat the seizures. Scientists increasingly recognize the importance of genetic factors in the origin of epilepsy. Genetics or heredity is most relevant to generalized seizures, including absence, generalized tonic-clonic and myoclonic seizures. Defects in genes don't directly lead to epilepsy, but they can alter the excitability of brain in a way to predispose to the seizures. Typically, epilepsy develops because of multiple gene abnormalities or because of a gene abnormality in concert with an environmental trigger. Parents with epilepsy wonder whether their children will have epilepsy (Gaby, 2007; Mock et al., 1998; Monaco et al., 1975; Nabbout et al., 1999; Nuytten et al., 1991; Ogunmekan, 1979; Ogunmekan et al., 1989; Pack and Morrell, 2001). In most cases they won't, but they do have a higher risk than others. If the mother has a generalized type of epilepsy, then the child's chance of having epilepsy may be as high as $5-20 \%$. But if a parent has epilepsy due to a brain injury, the child's chance of having epilepsy is only about $5 \%$ (Asadi-Pooya et al., 2008). Diet is a fundamental aspect of human life and patients with epilepsy often report or ask if foods are related to their illness. While foods are commonly considered dubious provoking agents for seizures, dietary and nutritional interventions are sometimes considered beneficial and even therapeutic. As antiepileptic drugs (AEDs) inadequately control seizures in many patients, some investigators have attempted nutritional supplementation in an effort to reduce seizure frequency or improve other aspects of health in patients with epilepsy. Nutrient supplementation may 
also be necessary to prevent or reverse the effects of certain deficiencies that might result from the use of AEDs. However, the potential benefits of nutrient supplementation in patients with epilepsy must be weighed against reports that large doses of certain nutrients (e.g., vitamin B6 and folic acid) can interfere with the effects of some AEDs (Gaby, 2007). This paper reviews dietary and nutritional considerations in patients with epilepsy and also the relationship among foods, dietary elements, and seizures. In this article, we will not discuss the ketogenic diet, which is the most accepted dietary treatment for epilepsy (Asadi-Pooya et al., 2008). There are several reports suggesting that certain foods might trigger seizures. However, the existing data are limited and controlled studies are lacking (Asadi-Pooya, 2005; Asadi-Pooya et al., 2006; Asadi-Pooya et al., 2005; Bankier et al., 1983; Kumandas et al., 2006; Kuo and Wang, 2002; Levy et al., 1990; Mintzer et al., 2006; Nicolai et al., 2006).

\section{NUTRITION AND EPILEPSY}

It is important that people with epilepsy follow a nutritious, well balanced diet. Good nutritional habits and a healthy lifestyle are important in obtaining optimal seizure control. However, no special diet is prescribed for epilepsy itself. To avoid dietary deficiencies, ensure proper intake of nutrients through a diet containing adequate folic acid (commonly found in raw and slightly cooked fruits and vegetables), calcium and magnesium (dairy products are the richest source), Vitamin B12 (animal and diary sources), and vitamin K (leafy green vegetables and cereal grains). Vitamin D is found in fish oils and flesh, supplemented milk, and is made in the body in response to sunlight. Rules for a healthy diet are outlined in "Canada's Food Guide". If you have some other condition in addition to epilepsy, that requires a special diet (diabetes, for example), it is important that you follow the diet needed for that disorder. The medicines that control seizures may interfere with the body's ability to use certain nutrients including vitamin $\mathrm{D}$, vitamin $\mathrm{K}$, calcium, magnesium, manganese and folic acid. While this problem is in most people who take medications, it is usually mild and causes no harm. Those most vulnerable to vitamin deficiencies include: people on large doses of medication or multiple drugs; the elderly; growing children; pregnant women; alcohol abusers; and those who follow poor dietary habits. If the body is depleted of these substances (calcium and magnesium), convulsions may occur. However, unless you have some other disease that affects these substances, you will not have problems with them if you eat a balanced, general diet (Tyagi and Delanty, 2003; Volpe et al., 2007; Yuen et al., 2005). As stated above, the use of anticonvulsants may have an adverse effect on vitamins. Problems can generally be avoided with a proper diet. However, in rare cases, more serious problems may arise. For example, anemia can result from severe folic acid deficiency. Weak bones are related to inadequate amounts of vitamin D. Vitamin deficiencies can be discovered by medical examination and laboratory screening. Vitamin supplements can be prescribed as necessary. Please note that self-diagnosis is discouraged. Extreme, self-prescribed "megavitamin" therapy will do no good and could be harmful. For example, excessive folic acid intake may actually decrease seizure control. "Ketogenic Diet" is a special, high fat diet approximates the metabolic circumstances of starvation. This state (in which the excessive fats produce chemicals called ketones) has been effective in controlling seizures in young children when anticonvulsants proved ineffective. The diet seldom works in children over 16 years of age and is not effective for all seizure types. The majority of caloric intake is obtained from fatty foods. It is quite unpalatable and difficult to maintain. Overall, it is reserved for children with epilepsy who are unresponsive to anticonvulsants. Another version of the diet has recently been developed - the medical chain triglyceride (MCT) diet (Kerr et al., 1994; Keyser and De Bruijn, 1991; Krause et al., 1982; Kroll, 1985; Mattson et al., 1973; Mikati et al., 1991; Miwa et al., 2001; Mock et al., 1997). In extreme cases, nevertheless, blood sugar level should be steady and moderate for people with epilepsy. Sweets, caffeine and alcohol all cause blood sugar levels to fluctuate and should be avoided. High fibrewhole wheat toast or a bran muffin-helps control fluctuations of blood sugar. Protein is also important in the metabolism of certain brain chemicals and hormones. Some individuals are sensitive to missing meals. If meals are missed or delayed, seizure frequency may increase. Therefore, regular meals and balanced diets are recommended. Substances (caffeine, alcohol or smoking) are best considered drugs rather than part of the diet. Like other drugs they can do harm, particularly if taken too often or in large amounts. Alcohol is of special concern. When used frequently or in large amounts, alcohol may interfere with the anticonvulsant medication and may lower seizure threshold. Having a seizure induced by smoking could lead to fire. Food allergies do not cause epilepsy. However, they may aggravate a pre-existing seizure problem (Tyagi and Delanty, 2003; Volpe et al., 2007; Yuen et al., 2005).

\section{Fruits}

The induction of seizures and refractory status epilepticus with a high mortality rate has been reported due to star fruit intoxication in patients with chronic renal disease. An excitatory neurotoxin from star fruit has been implicated although the exact nature of this toxic substance has not been identified. The most common symptoms of star fruit intoxication include intractable hiccups, vomiting, variable degrees of disturbed consciousness, psychiatric symptoms, decreased muscle power, paresthesia, paresis, insomnia, epileptic seizures, and death. The mortality rate after star fruit intoxication ranges as high as $20-40 \%$. As no effective treatment has been established, star fruit consumption should be avoided in patients with chronic renal disease, especially in the elderly.

\section{Amino acids}

Animal studies have reported the reduction of seizure threshold in rats administered with excess dietary amino acids (Gallagher et al., 1968) and the induction of convulsions by monosodium glutamate (Bhagavan et al., 1971). One case report indicated ingestion of monosodium glutamate appeared to trigger or exacerbate seizures in a child with Lennox-Gastaut syndrome (Shovic et al., 1997), though this had several limitations with regard to definition of the condition and methodology (Auer, 1998).

\section{Aspartame}

Several cases have suggested aspartame may provoke seizures, particularly in for phenyl ketonuria (PKU) (Camfield et al., 1992; Tyagi and Delanty, 2003). Of 18 individuals whose seizures were allegedly related to aspartame and who were monitored by continuous EEG, none experienced seizure exacerbation with aspartame $(50 \mathrm{mg} / \mathrm{kg})$, a dose that is much higher than expected in a regular diet. However, a potential limitation of this study, which was funded by the manufacturer of aspartame, is that aspartame was administered in capsules, rather than in foods or beverages. Aspartame in commercial products might undergo chemical changes on exposure to high temperatures or after storage (Gaby, 2007). It should be 
mentioned that the above-mentioned studies and similar reports are either anecdotal or animal studies; proconvulsive effects of foods have never been proved in randomized, controlled clinical trials in humans. Whether other, more commonly consumed edibles bring on seizures is even less certain (AsadiPooya et al., 2008).

\section{Caffeine}

There are anecdotal case reports of increased seizure frequency in patients with epilepsy due to ingestion of foods or beverages containing central nervous system stimulants (e.g., caffeine) (level $\mathrm{C}$ evidence). Caffeine blocks adenosine receptor and functions as a stimulant. Theoretically, this might be responsible for increased neuronal repetitive firing and seizures (Bonilha and Li, 2004; Kaufman and Sachdeo, 2003). However, caffeine has differential actions on different brain areas. It has inhibitory effects on the medial thalamus and excitatory effects on brain stem reticular formation (Chou et al., 1980). There is insufficient evidence to support its effects with regard to triggering seizures either in animal or human studies. A separate point is that, caffeine can induce hepatic CYP-1A enzymes, which are involved in the metabolism of many drugs including carbamazepine (Goasduff et al., 1996). Theoretically, this might lower serum drug levels and thereby increase the likelihood of having a seizure. Due to the widespread habit of coffee and tea drinking, further attention should be paid to the potential effects of caffeine in seizure control, but at the moment, there is not enough evidence to suggest that reduction of the daily intake of coffee or tea might help the treatment of patients with refractory seizures. Any recommendations should be tested by well-designed, randomized, placebo-controlled clinical studies. On the other hand, regardless of its effects on seizures, there is growing evidence that caffeine, like certain AEDs, can adversely affect bone density (Gissel et al., 2007). In a clinical study, it was reported that women with caffeine intakes > $300 \mathrm{mg} /$ day had higher bone loss, possibly due to decrease in vitamin $\mathrm{D}$ receptor protein expression. Caffeine consumption has been reported to decrease bone mineral density, increase the risk of hip fracture, and negatively influence calcium retention, possibly due to deleterious effects on the osteoblasts viability, which may enhance the rate of osteoblast apoptosis. Whether the effects of caffeine and AEDs on bone metabolism and density are additive has not been studied, but it may be prudent that patients with epilepsy, particularly those individuals with other risk factors for or evidence of decreased bone mineral density, avoid excessive intake of caffeine. Caffeine is found in coffee, tea, soft drinks, energy drinks, and chocolate (Asadi-Pooya et al., 2008).

\section{Carnitine}

Treatment of children with valproic acid, particularly in combination with other anticonvulsant drugs, reduced total and free carnitine concentrations and increased plasma ammonia concentrations (a manifestation of carnitine deficiency). Carnitine levels in patients taking anticonvulsants other than valproic acid were normal (Verrotti et al., 1999). A consensus statement by a panel of pediatric neurologists concluded that Lcarnitine supplementation is indicated for patients with symptomatic valproic acid-associated hyperammonemia, multiple risk factors for valproic acid hepatotoxicity, or renalassociated syndromes; infants and young children taking valproic acid; patients with epilepsy using the ketogenic diet who have low serum carnitine levels; patients receiving dialysis; and premature infants receiving total parenteral nutrition. The panel recommended an oral L-carnitine dosage of 100 $\mathrm{mg} / \mathrm{kg} / \mathrm{day}$, to a maximum of $2 \mathrm{~g} /$ day. Intravenous L-carnitine was recommended for valproic acid-induced hepatotoxicity, overdose, and other acute metabolic crises associated with carnitine deficiency. In one prospective study, two out of 13 valproate-treated children developed clinical symptoms (e.g., fatigue) and biochemical evidence of carnitine deficiency. In four others, an asymptomatic biochemical deficiency was found. If a patient complains of fatigue during prolonged valproic acid treatment, some practitioners advise carnitine supplementation. In addition, there are some preliminary data that support the hypothesis that 1-carnitine treatment significantly enhances the survival of patients with severe valproateinduced hepatotoxicity. Oral 1-carnitine supplementation is also suggested (level C evidence) for infants and young children receiving valproate, especially those younger than 2 years with a complex neurological disorder who are receiving multiple AEDs, patients who have multiple risk factors for hepatotoxicity (e.g., neurological impairments, poor nutrition, failure to thrive, chronic illness, receiving multiple AEDs), and those receiving dialysis (De Vivo et al., 1998).

\section{Food allergy}

Over the past few decades, a number of hypothesis that convulsions might be associated with allergy (certain foods or allergens) (Cunningham, 1975; Egger et al., 1989; Frediani et al., 2001), but others have refuted this hypothesis (Asadi-Pooya and Ghetmiri, 2007; Castaneda et al., 1998). So far, the evidence with regard to the relationship between epilepsy and allergic disorders is preliminary and more work is needed. However, if certain foods are reliably associated with seizures in an individual patient, avoiding the offending food might be tried, but proper nutritional intake should not be compromised. In case reports, specific foods were implicated in epilepsy causation; the avoidance of symptom-evoking foods resulted in a reduction in seizure frequency or elimination of seizures (Gaby, 2007; Reichelt et al., 1990). In a study of 63 children with epilepsy, identification and avoidance of allergenic foods was frequently successful for patients who had other symptoms suggestive of allergy, but not for children who had epilepsy alone. For four weeks, 63 children with epilepsy underwent an elimination diet consisting of lamb, chicken, potato, rice, banana, apple, cabbage, sprouts, cauliflower, broccoli, cucumber, celery, carrots, parsnips, water, salt, pepper, pure herbs, calcium, and vitamins. Of 18 children who had epilepsy alone, none improved. The other 45 children with epilepsy also had recurrent migraines, abdominal symptoms, or hyperkinetic behavior. Of those children, 55.6 percent stopped having seizures and an additional 24.4 percent had fewer seizures during diet therapy (a total of 80 percent with complete or partial resolution of seizures). Headaches, abdominal pains, and hyperkinetic behavior resolved in all patients whose seizures resolved, as well as in some patients who continued to have seizures. Symptoms were evoked by 42 different foods, and seizures occurred after ingestion of 31 different foods. Most children reacted to several foods. Both generalized epilepsy (including myoclonic seizures and petit mal) and partial epilepsy improved on the diet. In double-blind, placebocontrolled food challenges, symptoms recurred in 15 of 16 children, including seizures in eight cases, after ingestion of offending foods; whereas, no symptoms recurred when placebo was given (Eggeret al., 1989). The prevalence of celiac disease has been found to be higher in patients with epilepsy than in controls (Cronin et al., 1998). Seizures have improved in patients with celiac disease who consumed a gluten-free diet, but only when the diet was started soon after the onset of epilepsy (Gobbi et al., 1992). Most epileptic patients with celiac disease did not have gastrointestinal symptoms at the 
time of presentation, so testing for celiac disease should be considered even in the absence of such symptoms. Some patients with epilepsy and celiac disease have also been found to have cerebral calcifications, (Hernandez et al., 1998) the significance of which is not clear.

\section{Celiac disease}

Celiac disease is a multisystem autoimmune disorder triggered by the ingestion of gluten in genetically susceptible individuals. The prevalence of celiac disease has been found to be higher in patients with epilepsy than in controls (Cronin et al., 1998). In one report of 43 patients with celiac disease, epilepsy and cerebral calcifications (Gobbi et al., 1992), seizures were poorly responsive to AEDs. Gluten-free diet beneficially affected the course of epilepsy only when started soon after epilepsy onset. High index of suspicion is necessary for the diagnosis of celiac disease and investigation for this disease is recommended in patients with childhood partial epilepsy with occipital paroxysms (Labate et al., 2001). Serum antibodies to tissue transglutaminase are reliable markers that may be used for celiac disease screening (De Lecea et al., 1996).

\section{Food and drug interactions}

Food-drug interaction is an important and often unrecognized problem in clinical practice. Foods may alter the effects of drugs by interfering with pharmacokinetic processes, such as absorption and elimination. In one study (Garg et al., 1998), it was observed that grapefruit juice significantly increased carbamazepine serum level. Grapefruit juice increases the bioavailability of carbamazepine by inhibiting CYP3Aenzymes in gut wall and in the liver. Conversely, a number of environmental agents such as smoking, alcohol consumption, and dietary elements may induce hepatic drug-metabolizing enzymes, which may have significant consequences on the pharmacokinetics of certain drugs including some AEDs (Hewitt et al., 2007). A few studies have showed the effects of various foods on different hepatic enzymes (Hewitt et al., 2007; Hidaka et al., 2004; Kim et al., 2006). These foods might potentially affect the plasma levels of AEDs metabolized by hepatic enzymes, which may lead to either drug toxicity or inefficacy (Anderson, 2004). Future clinical studies investigating the interactions between foods and cytochrome P450 enzymes are necessary to determine whether inhibition or induction of these enzymes activity by foods is clinically relevant. However, the authors have seen several patients in which grapefruit juice appears to have produced clinical toxicity by increasing serumdrug levels.

\section{Other nutrients}

Manganese deficiency has been reported in patients with epilepsy, though it does not appear to correlate with seizure frequency or the type, dose, or plasma levels of AEDs (Carl et al., 1986). Omega-3 fatty acids increase seizure thresholds, and lower inflammatory mediators, which are increased in patients with epilepsy. Linolenic acid prevents kainate-induced seizures and neuronal death and has neuroprotective effects (Lauritzen et al., 2000). In a double-blind study (Yuen et al., 2005), supplementation with fish oil, providing omega-3 fatty acids, reduced seizure frequency during the first 6 weeks of treatment, but the beneficial effect was not sustained thereafter. In summary, large amounts of ginkgo nuts and the consumption of star fruit in patients with chronic renal disease may produce seizures; however, the relation between aspartame and other more commonly consumed edibles and seizures is unproven. The relation between diet and seizures should be considered in patients with celiac disease. Inpatients (particularly children) with occipital lobe epilepsy, it is recommended to screen for celiac disease. While pyridoxine, folic acid, and biotin supplementation is necessary in patients with cerebral folate deficiency, or biotinidase deficiency, respectively, there is no evidence to support their use in other circumstances, to control the seizures. Carnitine supplementation might be helpful in some patients who are taking valproate and low dose of folate supplement ationmay prevent carbamazepine-induced leukopenia or anemia. In addition, though evidence is lacking, the use of high dose of folic acid supplements in women with epilepsy before conception and during pregnancy, supplementation with vitamin $\mathrm{D}$ in patients taking enzymeinducing AEDs and valproate, and finally, vitamin $\mathrm{K}$ in pregnant women taking AEDs and their newborns are recommended. The relation between other nutrients (e.g., vitamin E and Omega-3 fatty acids and seizures) should be investigated further before asserting any recommendations. It should be mentioned that a food-drug interaction has been observed between grapefruit juice and carbamazepine. Clinical studies investigating the interactions between foods and cytochrome P450 enzymes are still needed to determine whether inhibition or induction of these enzymes activity is clinically relevant. It should be considered that, because there are many different types of epilepsy, a nutritional intervention that is helpful for one syndrome or seizure type might not be beneficial for another. On the other hand, unnecessary and excessive vitamin and mineral supplementation may actually be harmful. For many people with epilepsy a healthy, balanced diet is the best, but many patients have nutritional deficiencies. In one recent study, at least $30 \%$ of children with intractable epilepsy had intakes below the recommended dietary allowance for vitamins $\mathrm{D}, \mathrm{E}$, and $\mathrm{K}$, folate, calcium, and linoleic acid (Volpe et al., 2007). Health care professionals caring for patients with epilepsy, especially children with intractable epilepsy, should be aware of these nutritional recommendations and educate families to provide an adequate diet and/or consider vitamin/ mineral supplementation. Given the high probability of any patient not eating a well-balanced diet, routine vitamin supplementation with modest doses can be considered reasonable. Of course, cost-benefit ratio should always be considered and over consumption of vitamin supplements should be avoided (Asadi-Pooya et al., 2008; Gaby, 2007; Ralston et al., 1970; Reynolds et al., 1971; Said et al., 1989; Silver. 1975; Snaith et al., 1970; Steidl et al., 1987).

\section{DIETARY FACTORS}

\section{Hypoglycemia}

Seizures are a known manifestation of hypoglycemia (Monami et al., 2005). In patients with epilepsy, hypoglycemia might decrease the threshold for seizure development. In one study of 92 patients with epilepsy, 56.4 percent were found to have a subnormal fasting blood glucose concentration (Gaby, 2007). In addition, transient EEG abnormalities have been observed in some patients during a glucose tolerance test. These abnormalities occurred, not when the blood glucose level was at its lowest point, but at a time that insulin levels would have been expected to be elevated (Gaby, 2007). These EEG changes were hypothesized to result from insulin-induced transport of water and electrolytes into the brain, leading to cerebral hyperosmolality. While the observed EEG changes were not necessarily of the type associated with seizures, these findings raise the possibility that hyperinsulinemia could trigger seizures in patients with epilepsy (Craytonet al., 1981). Thus, hypoglycemia and hyperinsulinemia might each contribute to the pathogenesis of epilepsy in some cases. Patients with 
epilepsy who have evidence of these abnormalities might benefit from nutritional interventions, such as avoiding refined sugar, caffeine, and alcohol; eating frequently; consuming adequate amounts of protein; and supplementing with chromium, other trace minerals, magnesium, and B vitamins.

\section{Dietary provocative factors}

In some cases, epileptic seizures have been triggered by excessive alcohol intake (Wolf and Okujava, 1999). Two case reports indicate ingestion of monosodium glutamate appeared to trigger or exacerbate seizures in children (Shovic et al., 1997). Grand mal seizures have occurred after consumption of aspartame by people who had no prior history of epilepsy (Walton, 1986; Wurtman, 1985). Ingestion of a drink containing aspartame (40 mg/kg body weight) also exacerbated EEG spike-wave discharges in children with a history of absence seizures (Camfield et al., 1992). However, in trials funded by the NutraSweet Company (the manufacturer of aspartame), administration of aspartame (34 mg/kg/day for two weeks or a single dose of $50 \mathrm{mg} / \mathrm{kg}$ ) did not provoke seizures in patients with epilepsy or in people who reported a history of aspartame-induced seizures. A potential limitation of these trials is that aspartame was administered in capsules, rather than in soft drinks or other aspartame containing foods or beverages. As aspartame in commercial products is said to undergo chemical changes on exposure to high temperatures or after storage for more than two months, these degradation products may be partly responsible for the reported adverse effects of aspartame (Roberts, 1995). Therefore, symptoms that occur after ingestion of aspartame-containing commercial products or hot drinks to which aspartame has been added may not be reproducible by challenging with aspartame in capsules. Based on the available evidence, aspartame should be considered a potential trigger for seizures and should be excluded during an elimination diet.

\section{Ketogenic diet}

The ketogenic diet has been used since 1921 to control seizures in children who do not respond to anticonvulsant medications (Gasch, 1990; Hemingway et al., 2001; Tallian et al., 1998; Vining, 1999). The diet is calorie-restricted and provides a ratio of fat to (carbohydrate + protein) ranging from $2: 1$ to $5: 1$. The proportion of total energy derived from fat ranges from 82 - 92 percent. Consuming a ketogenic diet produces a state of ketosis, which helps control seizures through an unknown mechanism. Fluid intake is restricted to maintain urine specific gravity at $1.020-1.025$, since fluid intake dilutes blood ketones. In different studies, 40-70 percent of patients following the diet experienced at least a 50-percent reduction in seizure frequency, and 10-33 percent became seizure-free. In many cases, medications could be discontinued or the dosages decreased. Two children with acquired epileptic aphasia were also successfully treated with this diet (Gaby, 2007). According to some research, myoclonic epilepsy responds best to the ketogenic diet. However, another study found that the response to the diet did not vary significantly according to seizure type (Vining, 1999). The diet is most effective in children ages 2 - 5 years, although patients of other ages have also benefited (Gasch, 1990). To be effective, the diet must be followed strictly; if the patient discontinues it, seizures are likely to return within hours. Typically, treatment is initiated in the hospital, starting with a $36 \mathrm{~h}$ water fast to induce ketosis; however, some investigators have found that it is not necessary to begin the diet with a fast. The ketogenic diet is usually followed for about two years, after which the proportion of fat is reduced gradually over $6-9$ months to that of a regular diet.
After a patient has been on the diet for two years, seizures are less likely to recur on resumption of a normal diet. In some cases, the diet regimen is repeated if seizures recur. There are some drawbacks to the ketogenic diet. Supplementation with multivitamins, calcium, and iron is necessary to prevent nutritional deficiencies. In addition, the ketogenic diet is unpalatable and is difficult for parents to administer. While most ketogenic diet studies have been conducted in children, one trial investigated its effect in 11 adults (ages 19 - 45 years; median, 32.2 years) with refractory epilepsy. At eight months of follow-up, three patients had a 90-percent reduction in seizure frequency compared with baseline, three patients had a 50- to 89-percent decrease, and one patient had a less-than-50percent decrease. All types of seizures responded to the diet. Common adverse effects included constipation, menstrual irregularities, and increases in triglyceride levels and cholesterol/HDL ratios. The triglycerides of octanoic and decanoic acids (medium-chain triglycerides; MCTs) are more ketogenic than long-chain triglycerides present in dietary fats. Diets containing large proportions of MCTs (usually provided by supplementing with MCT oil) are also easier to prepare, more palatable, better tolerated, and require less carbohydrate and protein restriction than standard ketogenic diets. The MCT ketogenic diet, which provides 50 - 70 percent of total energy in the form of MCTs, has been used as an alternative to the classic ketogenic diet (Gordon, 1977; Huttenlocher et al., 1971; Trauner, 1985). In one study, adherence to this diet resulted in improvement or complete control of seizures in 44 percent of 50 children with drug-resistant epilepsy. Children who have had a positive response to this diet may be able to taper off the diet after 3-4 years without experiencing a recurrence of seizures. While the MCT diet is frequently well tolerated, some patients abandon it because of gastrointestinal intolerance.

\section{Ketogenic diet adverse effects}

The ketogenic diet has caused a number of adverse effects, some serious. Initiation of the diet can result in vomiting, hypoglycemia, or dehydration. In one study, serious adverse events (severe hypoproteinemia, Fanconi's renal tubular acidosis, or marked abnormalities on liver function tests) occurred in five of 52 children on a ketogenic diet. Other potential side effects include increased bruising or other minor bleeding (in association with a prolonged bleeding time), constipation, and diarrhea (Berry-Kravis et al., 2001; Edelstein, and Chisholm, 1996). Long-term problems include moderate growth retardation, renal stones (5 - 8\% of cases), gallstones, acidosis or metabolic problems (particularly during illness), recurrent infections, hyper-cholesterolemia, hyperuricemia, vitamin deficiency, and feeding problems. Prolonged ketosis may raise the serum level of phenobarbitone, which can result in alopecia, renal stones, and growth retardation (Gordon, 1977). The ketogenic diet and anticonvulsant drugs both have an adverse effect on bone density, which can be partially reversed with vitamin D supplementation. Carnitine deficiency may also occur with the ketogenic diet, particularly in patients taking valproic acid. L-carnitine supplementation is recommended for patients who have low serum carnitine levels (De Vivo et al., 1998). Patients on the ketogenic diet must be monitored closely by a practitioner experienced in its use.

\section{Atkins diet}

The Atkins diet is a low-carbohydrate, highfat diet used by millions of people for weight reduction. Like the ketogenic diet, the Atkins diet can induce a state of ketosis, but it has fewer restrictions on calories and protein. In addition, the Atkins diet does not require fluid restriction and does not need to be started 
in the hospital. According to one study, the Atkins diet may be an effective alternative to the ketogenic diet in some children with intractable epilepsy. Twenty children (ages 3 - 18 years) with intractable epilepsy, with at least three seizures per week, who had been treated with at least two anticonvulsants, followed a modified Atkins diet (nature of the modification not specified) over a six-month period. Carbohydrates were limited to $10 \mathrm{~g} /$ day for the first month and consumption of fats was encouraged. All children received vitamin and calcium supplements. At six months, 13 patients $(65 \%)$ had more than 50-percent improvement and seven patients (35\%) had more than 90-percent improvement (four were seizure-free). Small increases were seen in serum cholesterol and blood urea nitrogen levels during the study. In another study, two adults (ages 42 and 52) with epilepsy showed no improvement on the Atkins diet (Kossoff et al., 2003).

\section{NUTRITIONAL SUPPLEMENTS}

\section{Taurine}

Taurine acts as a modulator of membrane excitability in the central nervous system by inhibiting the release of other neurotransmitters and decreasing mitochondrial release of calcium (Gaby, 2007). Taurine concentrations have been found to be elevated in serum, but decreased in the brain, of some patients with epilepsy. In contrast, serum concentrations of most other amino acids were lower in patients with epilepsy than in healthy controls. Taurine administration partially corrected these low serum amino acid concentrations (Goodman et al., 1980; Monaco et al., 1975; Mutani et al., 1975; Van Gelder et al., 1975). Taurine has been administered orally or intravenously at a wide range of doses $(200 \mathrm{mg} /$ day to 21 $\mathrm{g} /$ day) for varying periods of time to patients with severe, intractable epilepsy. In some studies, a significant reduction in seizure frequency was observed (Barbeau et al., 1974; Bergamini et al., 1974; Gaby, 2007; Pennetta et al., 1977), whereas no benefit was seen in others (Mantovani and DeVivo, 1979). According to one report, taurine was effective against partial epilepsy but had little effect on generalized epilepsy. The beneficial effects of taurine frequently diminished or disappeared after a few weeks of treatment. One possible explanation for the loss of efficacy is that high-dose taurine caused amino acid imbalances, as suggested by the appearance of generalized aminoaciduria in a patient during treatment daily with $2.0-2.5 \mathrm{~g}$ taurine. It has been suggested that the optimal dose of taurine to treat epilepsy might be in the range of 100$500 \mathrm{mg} / \mathrm{day}$, and in one report a loss of antiseizure activity was seen in some patients when the dose was increased above 1.5 $\mathrm{g} /$ day. While additional studies are needed to determine taurine's optimal dosage range, no specific dosage regimen has been shown to produce long-lasting improvement of epilepsy.

\section{Dimethylglycine}

Dimethylglycine, a metabolite of betaine, demonstrated anticonvulsant activity in mice in one study (Freed, 1985), but not in another (Haidukewych and Rodin, 1984). In a case report, a 22-year-old mentally handicapped man with mixed complex, partial, and grand mal seizures had been having $16-18$ generalized seizures per week, despite therapeutic levels of phenobarbital and carbamazepine. His mother began giving him $90 \mathrm{mg}$ dimethyl-glycine twice daily because of a suggestion it might improve his stamina. Within one week his seizure frequency dropped to three per week. Two attempts to withdraw dimethylglycine resulted in a dramatic increase in seizures (Roach and Carlin, 1982). In follow-up studies, administration of dimethylglycine to 24 epileptic patients in doses of $300-810 \mathrm{mg} /$ day for up to 30 days did not produce any improvement (Gascon et al., 1989; Roach and Gibson. 1983). It was suggested that the one patient who benefited from dimethylglycine may have had an isolated metabolic defect that was overcome by treatment with this compound.

\section{Essential fatty acids}

Five severely mentally handicapped patients (ages 12 - 26 years) with more than 3 - 4 grand mal seizures per month received a daily supplement providing $900 \mathrm{mg}$ eicosapentaenoic acid (EPA), $2.3 \mathrm{~g}$ docosahexaenoic acid (DHA), and $50 \mathrm{mg}$ alphalinolenic acid. All five patients experienced a marked reduction in both frequency and severity of grand mal seizures (Schlanger et al., 2002). In a double-blind study that included 57 adults (mean age, 39 years), supplementation with fish oil (providing $1 \mathrm{~g} /$ day EPA and $0.7 \mathrm{~g} /$ day DHA) reduced seizure frequency during the first six weeks of treatment, but the beneficial effect was not sustained thereafter (Yuen et al., 2005). In contrast to the possible beneficial effect of omega- 3 fatty acids, the omega-6 fatty acids in evening primrose oil may have deleterious effects in some patients with epilepsy. There are several case reports in which administration of evening primrose oil appeared to exacerbate or unmask temporal lobe epilepsy (Holman and Bell, 1983; Vaddadi et al., 1986; Vaddadi, 1981).

\section{HORMONES}

\section{Melatonin}

In one study, $3 \mathrm{mg}$ melatonin was given each night for three months to six children (ages 2 - 15 years) with severe, intractable seizures. The mean seizure frequency decreased from 3.6 per day at baseline to 1.5 per day during treatment (58\% reduction; $p<0.05)$. Melatonin has also been used in doses of $2-10 \mathrm{mg}$ before bedtime to treat sleep disturbances in children with epilepsy. Melatonin treatment was associated with an increase in seizure frequency in some patients and a decrease in others (Jones et al., 2005; Sheldon, 1998). Because melatonin appears to have unpredictable effects on seizure frequency, it should be used with caution in patients with epilepsy.

\section{Progesterone}

According to one study, progesterone may be beneficial for women who have seizure exacerbations at specific times during the menstrual cycle. Twenty-five women with cyclic exacerbation of complex partial or secondary generalized motor seizures of temporal origin received progesterone lozenges (200 mg 3 times per day). Women with perimenstrual exacerbations received treatment on days 23 to 25 of each cycle women who had exacerbations during the entire luteal phase were treated from days 15 to 25 of each menstrual cycle. In both groups of women, progesterone was tapered after day 25 and discontinued by day 28 . Progesterone was well tolerated by 23 of the 25 women. Two women experienced asthenia and emotional depression, which resolved within one day of discontinuing treatment. Eighteen women $(72 \%)$ experienced a decline in seizure frequency during the three-month treatment period, compared with the three months prior to therapy $(p<$ 0.01 ). Among the 23 women who continued treatment, the average frequency of complex partial seizures declined by 54 percent $(p<0.01)$ and the frequency of secondary generalized motor seizures declined by 58 percent $(p<0.02)$ (Herzog, 1995). 


\section{DISCUSSION}

Epilepsy is a disorder of brain electrical activity that results in recurrent seizures. The type of seizure depends on the portion of the brain affected. While there are many different causes of seizures, including brain tumor, head injury, stroke, and alcohol withdrawal, the discussion in this article is limited mainly to cases in which the cause is idiopathic (primary epilepsy). Conventional treatment of epilepsy consists primarily of anticonvulsant medications. Although these drugs often control or reduce the frequency of seizures, some patients show little or no improvement. A number of dietary modifications, nutritional supplements, and hormones have been found to be beneficial for some patients with epilepsy. Potentially useful dietary interventions include measures to stabilize blood glucose levels, identification and avoidance of allergenic foods, and avoidance of potential inciting agents (such as ethanol and aspartame). The ketogenic diet has been successful for many patients, but because of its highly restrictive nature and potential to cause significant adverse effects, its use is restricted to severe cases that fail to respond to other treatments. A less restrictive version of the ketogenic diet, the Atkins diet, has shown promise and deserves further study (Gaby. 2007; Joshi et al., 1999; Peled et al., 2001; Peterson et al., 1976; Pfeiffer and LaMola. 1983; Raju et al., 1994; Sullivan et al., 1990; Tamai et al., 1988; Gaby, 2007; Torres et al., 1999; Trimble et al., 1980; Turner et al., 1977). Several different nutrients (and two hormones) may also be beneficial in selected patients with epilepsy. The fact that nutritional factors are involved in the regulation of electrical activity in the brain is indicated by the fact that severe deficiency of thiamine, magnesium, or vitamin B6 can cause seizures. A subnormal concentration of each of these nutrients has been found to be common in patients with epilepsy. While the severity of these deficiencies is probably not great enough in most cases to cause seizures in otherwise healthy people, marginal status with respect to any of these nutrients could conceivably exacerbate a seizure disorder due to another cause. In addition, some patients with epilepsy might have a higherthan-normal requirement for one or more nutrients that play a role in brain electrical activity. That phenomenon has been clearly demonstrated in the case of vitamin B6-dependent epilepsy, a condition in which intractable seizures can be completely controlled by administration of large doses of vitamin B6 (Afzal et al., 1985; Anderson. 2004; Bennett et al., 2005; Borges et al., 1978; Botez et al., 1993; Brown et al., 1991; Ch'ien et al., 1975; Christiansen et al., 1973). The existence of this relatively rare syndrome raises the possibility that more subtle forms of nutrient dependency occur more commonly (Gaby, 1984; Gaby, 1994). While mildly or moderately increased requirements for vitamin B6 or other nutrients may not by themselves be sufficient to cause seizures, a failure to meet these increased requirements could aggravate an existing seizure disorder. Some studies have found that supplementation with individual nutrients reduced seizure frequency or improved other aspects of health in patients with epilepsy, but other studies have failed to confirm those findings. Administration of combinations of nutrients might be more effective than supplementing with a single nutrient, but that possibility has largely been unexplored. Nutrient supplementation may also be necessary to prevent or reverse the effects of certain deficiencies that frequently result from the use of anticonvulsant drugs. The potential benefits of nutrient supplementation in patients with epilepsy must be weighed against reports that large doses of certain nutrients (such as vitamin B6 and folic acid) can interfere with the effects of anticonvulsants. Because there are many different types of epilepsy, a nutritional intervention that is helpful for one patient may not be beneficial for another. Some studies did not specify the types of epilepsy being treated, so it is difficult to generalize results (Christiansen and Rodbro, 1974; Clarke et al., 1979; Coker, 1992; Cornelissen et al., 1993; Crowell and Roach, 1983; Davis et al., 1975; Deb et al., 1987; Djukic, 2007; Dupont and Tanaka, 1985; Furlanut et al., 1978; Gibberd et al., 1981; Gospe, 2006). Nevertheless, natural approaches to the treatment of epilepsy show promise and should be considered as part of the overall treatment of epilepsy.

\section{ACKNOWLEDGEMENTS}

Authors are thankful to Department of Pharmacy, GRD(PG)IMT, Dehradun, India for providing the guidance and facilities to carry out this research work.

\section{CONFLICT OF INTEREST}

None to declare.

\section{REFERENCES}

Afzal S, Kalra G, Kazmi SH, Siddiqui MA. A study of serum and cerebrospinal fluid magnesium in convulsive disorders. $\mathbf{J}$ Assoc Physicians. 1985;33:161-163.

Anderson GD. Pharmacogenetics and enzyme induction/inhibition properties of antiepileptic drugs. Neurology. 2004;63:S3-S8.

Asadi-Pooya AA, Ghafari A. Do patients with epilepsy believe they need specific dietary restrictions? Epilepsy Behav, 2004;5:945-948.

Asadi-Pooya AA, Ghetmiri E. Allergy and idiopathic generalized epilepsy: a case-control study. J Pediatr Neurol. 2007;5:231-232.

Asadi-Pooya AA, Ghetmiri E. Folic acid supplementation reduces the development of some blood cell abnormalities in children receiving carbamazepine. Epilepsy Behav. 2006;8:228-231.

Asadi-Pooya AA, Hossein-Zade A. What do nurses and physicians think about the need for specific dietary restrictions in the patients with epilepsy?. Epilepsy Behav. 2005;6:604-606.

Asadi-Pooya AA, Mintzer S, Sperling MR. Nutritional supplements, foods, and epilepsy: Is there a relationship? Epilepsia. 2008;49:1819-1827.

Asadi-Pooya AA, Sperling MR. Do foods precipitate seizures?. A cross-cultural comparison. Epilepsy Behav. 2007;11:450-453.

Asadi-Pooya AA. Risk factors for carbamazepine-induced leucopenia in children and adolescents. J Pediatr Neurol. 2005;3:233-235.

Auer RN. Can eliminating monosodium glutamate from the diet affect Lennox-Gastaut syndrome?. J Am Diet Assoc. 1998;98:857.

Bankier A, Turner M, Hopkins IJ. Pyridoxine dependent 
seizures-a wider clinical spectrum. Arch Dis Child. 1983;58:415-418.

Barbeau A, Donaldson J. Zinc, taurine, and epilepsy. Arch Neurol. 1974;30:52-58.

Bennett CL, Huynh HM, Chance PF, Glass IA, Gospe SM Jr. Genetic heterogeneity for autosomal recessive pyridoxinedependent seizures. Neurogenetics. 2005;6:143-149.

Bergamini L, Mutani R, Delsedime M, Durelli L. First clinical experience on the antiepileptic action of taurine. Eur Neurol. 1974;11:261-269.

Berry-Kravis E, Booth G, Taylor A, Valentino LA. Bruising and the ketogenic diet: evidence for dietinduced changes in platelet function. Ann Neurol. 2001;49:98-103.

Bhagavan HN, Coursin DB, Stewart CN. Monosodium glutamate induces convulsive disorders in rats. Nature. 1971;232:275-276.

Bonilha L, Li LM. Heavy coffee drinking and epilepsy. Seizure. 2004;13:284-285.

Borges LF, Gücer G. Effect of magnesium on epileptic foci. Epilepsia. 1978;19:81-91.

Botez MI, Botez T, Ross-Chouinard A, Lalonde R. Thiamine and folate treatment of chronic epileptic patients: a controlled study with the Wechsler IQ scale. Epilepsy Res. 1993;16:157163.

Brown RS, Di Stanislao PT, Beaver WT, Bottomley WK. The administration of folic acid to institutionalized epileptic adults with phenytoininduced gingival hyperplasia. A double-blind, randomized, placebo-controlled, parallel study. Oral Surg Oral Med Oral Pathol. 1991;71:565-568.

Camfield PR, Camfield CS, Dooley JM, Gordon K, Jollymore $\mathrm{S}$, Weaver DF. Aspartame exacerbates EEG spike-wave discharge in children with generalized absence epilepsy: a double-blind controlled study. Neurology. 1992;42:1000-1003.

Carl GF, Keen CL, Gallagher BB, Clegg MS, Littleton WH, Flannery DB, Hurley LS. Association of low blood manganese concentrations with epilepsy. Neurology. 1986;36:1584-1587.

Castaneda GY, Heilbroner PL, Shah N, Forem S, Fish I. Asthma and epilepsy: are they related? A retrospective study. J Child Neurol. 1988;13:283-285.

Ch'ien LT, Krumdieck CL, Scott CW Jr, Butterworth CE Jr. Harmful effect of megadoses of vitamins: electroencephalogram abnormalities and seizures induced by intravenous folate in drug-treated epileptics. Am J Clin Nutr. 1975;28:51-58.

Chou DT, Forde JH, Hirsh KR. Unit activity in medial thalamus: comparative effects of caffeine an amphetamine. J Pharmacol Exp Ther. 1980;213:580-585.

Christiansen C, Rodbro P, Lund M. Incidence of anticonvulsant osteomalacia and effect of vitamin D: controlled therapeutic trial. Br Med J. 1973;4:695-701.
Christiansen C, Rodbro P, Sjö O. "Anticonvulsant action" of vitamin $\mathrm{D}$ in epileptic patients? A controlled pilot study. $\mathrm{Br}$ Med J. 1974;2:258-259.

Clarke TA, Saunders BS, Feldman B. Pyridoxine-dependent seizures requiring high doses of pyridoxine for control. Am J Dis Child. 1979;133:963-965.

Coker SB. Postneonatal vitamin B6-dependent epilepsy. Pediatrics. 1992;90:221-223.

Cornelissen M, Steegers-Theunissen R, Kollée L, Eskes T, Motohara K, Monnens L. Supplementation of vitamin K in pregnant women receiving anticonvulsant therapy prevents neonatal vitamin $\mathrm{K}$ deficiency. Am $\mathrm{J}$ Obstet Gynecol. 1993; $168: 884-888$

Crayton JW, Stone T, Stein G. Epilepsy precipitated by food sensitivity: report of a case with double-blind placebocontrolled assessment. Clin Electroencephalogr. 1981;12:192198.

Cronin CC, Jackson LM, Feighery C, Shanahan F, Abuzakouk M, Ryder DQ, Whelton M, Callaghan N. Celiac disease and epilepsy. QJM. 1998;91:303-308.

Crowell GF, Roach ES. Pyridoxine-dependent seizures. Am Fam Physician. 1983;27:183-187.

Cunningham AS. Allergy, immunodeficiency, and epilepsy. Lancet. 1975;2:975.

Davis RE, Reed PA, Smith BK. Serum pyridoxal, folate, and vitamin B12 levels in institutionalized epileptics. Epilepsia. 1975;16:463-468.

De Lecea A, Ribes-Koninckx C, Polanco I, Calvete JF. Serological screening for non-overt coeliac disease in children of short stature. Acta Paediatr Suppl. 1996;412:54-55.

De Vivo DC, Bohan TP, Coulter DL, Dreifuss FE, Greenwood RS, Nordli DR Jr, Shields WD, Stafstrom CE, Tein I. Lcarnitine supplementation in childhood epilepsy: current perspectives. Epilepsia. 1998;39:1216-1225.

Deb S, Cowie VA, Richens A. Folate metabolism and problem behaviour in mentally handicapped epileptics. J Ment Defic Res. 1987;31:163-168.

Djukic A. Folate-responsive neurologic diseases. Pediatr Neurol. 2007;37:387-397.

Dupont CL, Tanaka Y. Blood manganese levels in children with convulsive disorder. Biochem Med. 1985;33:246-255.

Edelstein SF, Chisholm M. Management of intractable childhood seizures using the non-MCT oil ketogenic diet in 20 patients. J Am Diet Assoc. 1996;96:1181-1182.

Egger J, Carter CM, Soothill JF, Wilson J. Oligoantigenic diet treatment of children with epilepsy and migraine. J Pediatr. 1989;114:51-58.

Frediani T, Lucarelli S, Pelliccia A, Vagnucci B, Cerminara C, Barbato M, Cardi E. Allergy and childhood epilepsy: a close relationship?. Acta Neurol Scand. 2001;104:349-352. 
Freed WJ. Prevention of strychnine-induced seizures and death by the N-methylated glycine derivatives betaine, dimethylglycine and sarcosine. Pharmacol Biochem Behav. 1985;22:641-643.

Furlanut M, Benetello P, Avogaro A, Dainese R. Effects of folic acid on phenytoin kinetics in healthy subjects. Clin Pharmacol Ther. 1978;24:294-297.

Gaby AR. Magnesium. (New Canaan, USA: Keats Publishing), 1994.

Gaby AR. Natural Approaches to Epilepsy. Altern Med Rev. 2007;12:9-24.

Gaby AR. The Doctor's Guide to Vitamin B6. (Emmaus, USA: Rodale Press), 1984.

Gallagher BB, Prichard JW, Glaser GH. Seizure threshold and excess dietary amino acids. Neurology. 1968;18:208-212.

Garg SK, Kumar N, Bhargava VK, Prabhakar SK. Effect of grapefruit juice on carbamazepine bioavailability in patients with epilepsy. Clin Pharmacol Ther. 1998;64:286-288.

Gasch AT. Use of the traditional ketogenic diet for treatment of intractable epilepsy. J Am Diet Assoc. 1990;90:1433-1434.

Gascon G, Patterson B, Yearwood K, Slotnick H. N,N dimethylglycine and epilepsy. Epilepsia. 1989;30:90-93.

Gibberd FB, Nicholls A, Wright MG. The influence of folic acid on the frequency of epileptic attacks. Eur J Clin Pharmacol 1981;19:57-60.

Gissel T, Poulsen CS, Vestergaard P. Adverse effects of antiepileptic drugs on bone mineral density in children. Expert Opin Drug Saf. 2007;6:267-278.

Goasduff T, Dréano Y, Guillois B, Ménez JF, Berthou F. Induction of liver and kidney CYP1A1/1 A2 by caffeine in rat. Biochem Pharmacol. 1996;52:1915-1919.

Gobbi G, Bouquet F, Greco L, Lambertini A, Tassinari CA, Ventura A, Zaniboni MG. Celiac disease, epilepsy, and cerebral calcifications. The Italian Working Group on Coeliac Disease and Epilepsy. Lancet. 1992;340:439-443.

Goodman HO, Connolly BM, McLean W, Resnick M. Taurine transport in epilepsy. Clin Chem. 1980;26:414-419.

Gordon N. Medium-chain triglycerides in a ketogenic diet. Dev Med Child Neurol. 1977;19:535-538.

Gospe SM Jr. Pyridoxine-dependent seizures: new genetic and biochemical clues to help with diagnosis and treatment. Curr Opin Neurol. 2006;19:148-153.

Goutiéres F, Aicardi J. Atypical presentations of pyridoxinedependent seizures: a treatable cause of intractable epilepsy in infants. Ann Neurol. 1985;17:117-120.

Grant ECG. Epilepsy and manganese. Lancet. 2004;363:572.

Grant RH, Stores OP. Folic acid in folate-deficient patients with epilepsy. Br Med J. 1970;4:644-648.
Guidolin L, Vignoli A, Canger R. Worsening in seizure frequency and severity in relation to folic acid administration. Eur J Neurol. 1998;5:301-303.

Haidukewych D, Rodin EA. N,N-dimethylglycine shows no anticonvulsant potential. Ann Neurol. 1984;15:405.

Hansson O, Sillanpaa M. Letter: Pyridoxine and serum concentration of phenytoin and phenobarbitone. Lancet. $1976 ; 1: 256$.

Hemingway C, Freeman JM, Pillas DJ, Pyzik PL. The ketogenic diet: a 3- to 6-year follow-up of 150 children enrolled prospectively. Pediatrics. 2001;108: 898-905.

Hernández MA, Colina G, Ortigosa L. Epilepsy, cerebral calcifications and clinical or subclinical celiac disease. Course and follow up with gluten-free diet. Seizure. 1998;7:49-54.

Herzog AG. Progesterone therapy in women with complex partial and secondary generalized seizures. Neurology. $1995 ; 45: 1660-1662$.

Hewitt NJ, Lecluyse EL, Ferguson SS. Induction of hepatic cytochrome P450 enzymes: methods, mechanisms, recommendations, and in vitro-in vivo correlations. Xenobiotica. 2007;37:1196-1224.

Hidaka M, Fujita K, Ogikubo T, Yamasaki K, Iwakiri T, Okumura M, Kodama H, Arimori K. Potent inhibition by star fruit of human cytochrome P450 3A (CYP3A) activity. Drug Metab Dispos. 2004;32:581-583.

Higashi A, Tamari H, Ikeda T, Ohtani Y, Matsukura M, Miyoshino S, Matsuda I. Serum vitamin E concentration in patients with severe multiple handicaps treated with anticonvulsants. Pediatr Pharmacol (New York). 1980;1:129134.

Hiilesmaa VK, Teramo K, Granström ML, Bardy AH. Serum folate concentrations during pregnancy in women with epilepsy: relation to antiepileptic drug concentrations, number of seizures, and fetal outcome. Br Med J (Clin Res ed).1983;287:577-579.

Holman CP, Bell AF. A trial of evening primrose oil in the treatment of chronic schizophrenia. J Orthomolecular Psychiatry. 1983;12:302-304.

Hom AC, Weaver RC, Alderson JJ. Efficacy of D-alpha tocopherol acetate as adjunctive antiepileptic agent in patients with refractory epilepsy and profound developmental disability: a prospective, randomized, double-blind, placebo-controlled trial. Epilepsia. 1991;32:S62.

Huttenlocher PR, Wilbourn AJ, Signore JM. Mediumchain triglycerides as a therapy for intractable childhood epilepsy. Neurology. 1971;21:1097-1103.

Johnson GM. Powdered goat's milk: pyridoxine deficiency and status epilepticus. Clin Pediatr (Phila). 1982;21:494-495.

Jones C, Huyton M, Hindley D. Melatonin and epilepsy. Arch Dis Child. 2005;90:1203.

Joshi S, al-Essa MA, Archibald A, Ozand PT. Biotinidase deficiency: a treatable genetic disorder in the Saudi population. 
East Mediterr Health J. 1999;5:1213-1217.

Kaufman KR, Sachdeo RC. Caffeinated beverages and decreased seizure control. Seizure. 2003;12:519-521.

Kerr BM, Thummel KE, Wurden CJ, Klein SM, Kroetz DL, Gonzalez FJ, Levy RH. Human liver carbamazepine metabolism. Role of CYP3A4 and CYP2C8 in 10,11-epoxide formation. Biochem Pharmacol. 1994;47:1969-1979.

Keyser A, De Bruijn SF. Epileptic manifestations and vitamin B1 deficiency. Eur Neurol. 1991;31:121-125.

Kim H, Yoon YJ, Shon JH, Cha IJ, Shin JG, Liu KH. Inhibitory effects of fruit juices on CYP3A activity. Drug Metab Dispos. 2006;34:521-523.

Kossoff EH, Krauss GL, McGrogan JR, Freeman JM. Efficacy of the Atkins diet as therapy for intractable epilepsy. Neurology. 2003;61:1789-1791.

Krause KH, Berlit P, Bonjour JP. Impaired biotin status in anticonvulsant therapy. Ann Neurol. 1982;12:485-486.

Kroll JS. Pyridoxine for neonatal seizures: an unexpected danger. Dev Med Child Neurol. 1985;27:377-379.

Kumandas S, Koklu E, Gümüs H, Koklu S, Kurtoglu S, Karakukcu M, Keskin M. Effect of carbamezapine and valproic acid on bone mineral density, IGF-I and IGFBP-3. J Pediatr Endocrinol Metab. 2006;19:529-534.

Kuo MF, Wang HS. Pyridoxal phosphate-responsive epilepsy with resistance to pyridoxine. Pediatr Neurol. 2002;26:146-147.

Labate A, Gambardella A, Messina D, Tammaro S, Le Piane E, Pirritano D, Cosco C, Doldo P, Mazzei R, Oliveri RL, Bosco D, Zappia M, Valentino P, Aguglia U, Quattrone A. Silent celiac disease in patients with childhood localization-related epilepsies. Epilepsia. 2001;42:1153-1155.

Lauritzen I, Blondeau N, Heurteaux C, Widmann C, Romey G, Lazdunski M. Polyunsaturated fatty acids are potent neuroprotectors. EMBO J. 2000;19:1784-1793.

Levy SL, Burnham WM, Hwang PA. An evaluation of the anticonvulsant effects of vitamin E. Epilepsy Res. 1990;6:1217.

Mantovani J, DeVivo DC. Effects of taurine on seizures and growth hormone release in epileptic patients. Arch Neurol. 1979;36:672-674.

Mattson RH, Gallagher BB, Reynolds EH, Glass D. Folate therapy in epilepsy. A controlled study. Arch Neurol. 1973;29:78-81.

Mikati MA, Trevathan E, Krishnamoorthy KS, Lombroso CT. Pyridoxine-dependent epilepsy: EEG investigations and longterm follow-up. Electroencephalogr Clin Neurophysiol. 1991;78:215-221.

Mintzer S, Boppana P, Toguri J, DeSantis A. Vitamin D levels and bone turnover in epilepsy patients taking carbamazepine or oxcarbazepine. Epilepsia. 2006;47:510-515.
Miwa H, Iijima M, Tanaka S, Mizuno Y. Generalized convulsions after consuming a large amount of Gingko nuts. Epilepsia. 2001;42:280-281

Mock DM, Dyken ME. Biotin catabolism is accelerated in adults receiving long-term therapy with anticonvulsants. Neurology. 1997;49:1444-1447.

Mock DM, Mock NI, Nelson RP, Lombard KA. Disturbances in biotin metabolism in children undergoing long-term anticonvulsant therapy. J Pediatr Gastroenterol Nutr. 1998;26:245-250.

Monaco F, Mutani R, Durelli L, Delsedime M. Free amino acids in serum of patients with epilepsy: significant increase in taurine. Epilepsia. 1975;16:245-249.

Monami M, Mannucci E, Breschi A, Marchionni N. Seizures as the only clinical manifestation of reactive hypoglycemia: a case report. J Endocrinol Invest. 2005;28:940-941.

Mutani R, Monaco F, Durelli L, Delsedime M. Levels of free amino acids in serum and cerebrospinal fluid after administration of taurine to epileptic and normal subjects. Epilepsia. 1975;16:765-769.

Nabbout R, Soufflet C, Plouin P, Dulac O. Pyridoxine dependent epilepsy: a suggestive electroclinical pattern. Arch Dis Child Fetal Neonatal Ed. 1999;81:F125-129.

Nicolai J, van Kranen-Mastenbroek VH, Wevers RA, Hurkx WA, Vles JS. Folinic acid-responsive seizures initially responsive to pyridoxine. Pediatr Neurol. 2006;34:164-167.

Nuytten D, Van Hees J, Meulemans A, Carton H. Magnesium deficiency as a cause of acute intractable seizures. J Neurol. 1991;238:262-264.

Ogunmekan AO, Hwang PA. A randomized, doubleblind, placebo-controlled, clinical trial of d-alphatocopheryl acetate (vitamin E), as add-on therapy, for epilepsy in children. Epilepsia. 1989;30:84-89.

Ogunmekan AO. Vitamin E deficiency and seizures in animals and man. Can J Neurol Sci. 1979;6:43-45.

Pack AM, Morrell MJ. Adverse effects of antiepileptic drugs on bone structure: epidemiology, mechanisms and therapeutic implications. CNS Drugs. 2001;15:633-642.

Peled N, Shorer Z, Peled E, Pillar G. Melatonin effect on seizures in children with severe neurologic deficit disorders. Epilepsia. 2001;42:1208-1210.

Pennetta R, Masi G, Perniola T, Ferrannini E. Electroclinical evaluation of the anti-epileptic action of taurine. Acta Neurol (Napoli). 1977;32:316-322.

Peterson P, Gray P, Tolman KG. Calcium balance in druginduced osteomalacia: response to vitamin D. Clin Pharmacol Ther. 1976;19:63-67.

Pfeiffer CC, LaMola S. Zinc and manganese in the schizophrenias. J Orthomolecular Psychiatry. 1983;12:215-234.

Raju GB, Behari M, Prasad K, Ahuja GK. Randomized, 
double-blind, placebo-controlled, clinical trial of D-alphatocopherol (vitamin E) as add-on therapy in uncontrolled epilepsy. Epilepsia. 1994;35:368-372.

Ralston AJ, Snaith RP, Hinley JB. Effects of folic acid on fitfrequency and behaviour in epileptics on anticonvulsants. Lancet. 1970;295:867-868.

Reichelt KL, Ekrem J, Scott H. Gluten, milk proteins and autism: dietary intervention effects on behavior and peptide secretion. J Appl Nutr. 1990;42:1-11.

Reynolds EH, Preece J, Johnson AL. Folate metabolism in epileptic and psychiatric patients. J Neurol Neurosurg Psychiatry. 1971;34:726-732.

Roach ES, Carlin L. N,N-dimethylglycine for epilepsy. N Engl J Med. 1982;307:1081-1082.

Roach ES, Gibson P. Failure of N,N-dimethylglycine in epilepsy. Ann Neurol. 1983;14:347.

Roberts HJ. Aspartame and headache. Neurology. 1995;45:1631.

Said HM, Redha R, Nylander W. Biotin transport in the human intestine: inhibition by anticonvulsant drugs. Am J Clin Nutr. 1989;49:127-131.

Schlanger S, Shinitzky M, Yam D. Diet enriched with omega-3 fatty acids alleviates convulsion symptoms in epilepsy patients. Epilepsia. 2002;43:103-104

Sheldon SH. Pro-convulsant effects of oral melatonin in neurologically disabled children. Lancet. 1998;351:1254.

Shovic A, Bart RD, Stalcup AM. "We think your son has Lennox-Gastaut syndrome'-a case study of monosodium glutamate's possible effect on a child. J Am Diet Assoc. 1997;97:793-794.

Silver J. Letter: Vitamin D therapy for children on anticonvulsants. N Engl J Med. 1975;293:1106.

Snaith RP, Mehta S, Raby AH. Serum folate and vitamin B12 in epileptics with and without mental illness. Br J Psychiatry. 1970;116:179-183.

Steidl L, Tolde I, Svomová V. Metabolism of magnesium and zinc in patients treated with antiepileptic drugs and with magnesium lactate. Magnesium. 1987;6:284-295.

Sullivan C, Capaldi N, Mack G, Buchanan N. Seizures and natural vitamin E. Med J Aust. 1990;152:613-614.

Tallian KB, Nahata MC, Tsao CY. Role of the ketogenic diet in children with intractable seizures. Ann Pharmacother. 1998;32:349-361.
Tamai H, Wakamiya E, Mino M, Iwakoshi M. Alphatocopherol and fatty acid levels in red blood cells in patients treated with antiepileptic drugs. J Nutr Sci Vitaminol (Tokyo). 1988;34:627631.

Torres OA, Miller VS, Buist NM, Hyland K. Folinic acidresponsive neonatal seizures. J Child Neurol. 1999;14:529-532.

Trauner DA. Medium-chain triglyceride (MCT) diet in intractable seizure disorders. Neurology. 1985;35:237- 238.

Trimble MR, Corbett JA, Donaldson D. Folic acid and mental symptoms in children with epilepsy. J Neurol Neurosurg Psychiatry. 1980;43:1030-1034.

Turner TL, Cockburn F, Forfar JO. Magnesium therapy in neonatal tetany. Lancet. 1977;1:283-284.

Tyagi A, Delanty N. Herbal remedies, dietary supplements and seizures. Epilepsia. 2003;44:228-235.

Vaddadi KS, Gilleard CJ, Mindham RH, Butler R. A controlled trial of prostaglandin E1 precursor in chronic neuroleptic resistant schizophrenic patients. Psychopharmacology (Berl). 1986;88:362-367.

Vaddadi KS. The use of gamma-linolenic acid and linoleic acid to differentiate between temporal lobe epilepsy and schizophrenia. Prostaglandins Med. 1981;6:375-379.

Van Gelder NM, Sherwin AL, Sacks C, Anderman F. Biochemical observations following administration of taurine to patients with epilepsy. Brain Res. 1975;94:297-306.

Verrotti A, Greco R, Morgese G, Chiarelli F. Carnitine deficiency and hyperammonemia in children receiving valproic acid with and without other anticonvulsant drugs. Int J Clin Lab Res. 1999;29:36-40.

Vining EP. Clinical efficacy of the ketogenic diet. Epilepsy Res. 1999;37:181-190.

Volpe SL, Schall JI, Gallagher PR, Stallings VA, Bergqvist AG. Nutrient intake of children with intractable epilepsy compared with healthy children. J Am Diet Assoc. 2007;107:1014-1018.

Walton RG. Seizure and mania after high intake of aspartame. Psychosomatics. 1986;27:218-220.

Wolf P, Okujava N. Possibilities of non-pharmacological conservative treatment of epilepsy. Seizure. 1999;8:45-52.

Wurtman RJ. Aspartame: possible effect on seizure susceptibility. Lancet. 1985;2:1060.

Yuen AW, Sander JW, Fluegel D, Patsalos PN, Bell GS, Johnson T, Koepp MJ. Omega-3 fatty acid supplementation in patients with chronic epilepsy: a randomized trial. Epilepsy Behav. 2005;7:253-258. 